\title{
AC 2010-866: INCORPORATING PROBLEM BASED LEARNING (PBL) IN A FRESHMAN ENGINEERING COURSE: METHODS FOR CLASSIFYING AND ASSESSING PBL PROJECTS
}

\author{
Javarro Russell, James Madison University \\ JAVARRO RUSSELL is a doctoral student in the Assessment and Measurement program at \\ James Madison University. As a Graduate Assistant for the Center for Assessment and Research \\ Studies, he serves as an assessment consultant to academic programs. In this role, he provides \\ guidance in assessment design and guidance in analyzing assessment results. He also serves as a \\ coordinator of large scale assessments at the university. His research interests are Assessment and \\ Public Policy, Use of Assessment Results, and Validity.
}

\section{Olga Pierrakos, James Madison University}

OLGA PIERRAKOS is an assistant professor in the new School of Engineering, which welcomed it inaugural class August 2008, at James Madison University. Dr. Pierrakos holds a B.S. in Engineering Science and Mechanics, an M.S. in Engineering Mechanics, and a Ph.D. in Biomedical Engineering from Virginia Tech. Her interests in engineering education research center around recruitment and retention, understanding engineering students through the lens of identity theory, advancing problem based learning methodologies, assessing student learning, as well as understanding and integrating complex problem solving in undergraduate engineering education. This latter project is funded through her recent NSF CAREER award. Her other research interests lie in cardiovascular fluid mechanics, sustainability research, and K-12 engineering outreach.

\section{Megan France, James Madison University}

MEGAN FRANCE is a doctoral student in the Assessment and Measurement program at James Madison University. As a Graduate Assistant for the Center for Assessment and Research Studies, she serves as an assessment consultant to academic programs and serves as a graduate research assistant on engineering education related research.

\section{Ronald Kander, James Madison University}

Ronald Kander is professor and Director of the School of Engineering at James Madison University where he teaches and does research in the area of polymer processing, manufacturability, and rapid prototyping/tooling technologies. He received a BS in Chemical Engineering from Carnegie-Mellon University in 1980, and a $\mathrm{PhD}$ in Chemical Engineering from the University of Delaware in 1987.

\section{Robin Anderson, James Madison University}

ROBIN ANDERSON is a professor and practitioner in Center for Assessment and Research Studies where she serves as the Associate Director. Previous to serving at James Madison University, Dr. Anderson worked with Blue Ridge Community College and the Virginia Community College System where she coordinated the System's core competency assessments. Dr. Anderson started the Journal of Research and Practice in Assessment and currently serves as the President of the Virginia Assessment Group.

\section{Heather Watson, James Madison University}

HEATHER WATSON is an assistant professor in the School of Engineering at James Madison University. She holds a Ph.D. from New Mexico State University, an M.S. from Georgia Institute of Technology, and a B.S. from the University of Detroit in Mechanical Engineering. Her research interests include renewable energy systems, thermal management systems, energy efficiency, and recruitment and retention in engineering education. 


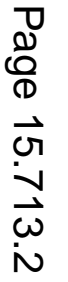




\title{
Incorporating Problem Based Learning (PBL) in a Freshman Engineering Course: Implementing Methods for Classifying and Assessing PBL Projects
}

\begin{abstract}
Problem-based learning (PBL), a powerful student-centered pedagogy, offers a strong framework upon which to build a curriculum that will allow students to learn essential problem solving skills. Although PBL methodologies are highly valued, they are not well integrated throughout the engineering education curriculum. This lack of integration stems from unclear classification of the type of projects that constitutes PBL practice. The lack of integration is further diminished by the deficit of assessment studies used to describe the efficacy of the PBL in assisting students in achieving learning outcomes. With a focus on a PBL-based freshman engineering course, in this paper we present:

(1) The novel use of a PBL classification framework grounded on dimensions of structuredness, complexity, and team environment.

(2) Assessment strategies for analyzing the alignment between the PBL learning experiences and the intended student learning outcomes.

(3) The classification and assessment of a freshman PBL project focused on reverse engineering a hand-held mixer.

(4) Suggestions on how PBL projects such as the reverse engineering example can be reshaped to meet a span of learning outcomes for engineering students.
\end{abstract}

In summary, what we hope to illustrate in this paper is that structure meets function - that is problem structure influences student learning. Novel use of PBL theory on problem classification enables us to capture how the structure of a problem shapes student learning outcomes. The implications of such an effort to utilize a PBL classification framework and assessment methods are that the tools developed herein can be used by engineering programs nationwide, independent of discipline or academic level.

\section{Introduction}

As a powerful student-centered pedagogy, problem-based learning (PBL) offers a strong framework upon which to build a curriculum. Some of the benefits of PBL ${ }^{1-2}$ include: (1) improving students' problem solving and critical thinking skills, (2) promoting high motivation for students, (3) increasing the ability to integrate and apply engineering skills with fundamentals of math and science, (4) enhancing the acquisition and retention of knowledge, and (5) facilitating collaborative learning.

Yet, although widely used in engineering, particularly during the senior year, PBL practices have not extensively been integrated throughout engineering curricula, and limited studies exist to provide sufficient support for PBL. This lack of integration is the result of poor classification of what constitutes PBL practice, and how such experiences can be integrated throughout the curriculum. Consequently, when used, PBL projects have taken different forms from program to program and course to course. These differences stem from differing philosophies about the use 
of PBL, the learning outcomes that are addressed through the use of PBL, and the creativity of those implementing PBL. For example, many believe that PBL refers to only open-ended problems that incorporate collaborative learning ${ }^{3-4}$. It is our belief, though, that PBL should have a broader definition because after all there are many types of problems $s^{5}$ - structured, unstructured, well-defined, ill-defined, simple, complex, team-based, individual, disciplinary, interdisciplinary, etc. - and herein we show the implementation of a classification framework for PBL practice.

The initial step toward reconciling these differences in PBL is to understand the projects that currently contribute to PBL practice. This understanding involves the classification of these PBL projects based on their educational attributes. The classification of projects is necessary to help identify the extent to which a variety of projects aid in the achievement of course and program objectives. By understanding which projects contribute to which learning outcomes, faculty can easily identify the projects that need to be re-worked if the desired student learning outcomes are not achieved. Unfortunately, the tools for classifying PBL projects are largely unavailable, especially for PBL projects specific to undergraduate engineering.

One reason for the unavailability of tools used for classifying PBL projects is the lack of program and course assessment studies for those implementing PBL. PBL-driven assessment should (1) be based in a practice context, (2) reflect the students' development from novice to an expert practitioner, and (3) engage in self-assessment and reflection ${ }^{6}$. Assessment at the program and course level provides opportunities for engineering educators to assess the types of PBL projects they are using. These assessment processes identify how well learning outcomes are being obtained by the students. By applying assessment methods to PBL projects and understanding how learning outcomes are met, programs can uncover appropriate ways to classify and compare projects.

It is well known that the assessment of student learning outcomes related to PBL projects is difficult to measure ${ }^{7}$. The skills taught through PBL are emergent and at times difficult to pinpoint. However, it is our ability to identify and assess those skills that allows us to enhance our programs to meet the needs of the students and the engineering community. Herein, we address these issues related to the implementation, classification, and the assessment of PBL through novel implementation of PBL theory pertinent to problem classification. The PBL experience we use to illustrate the PBL classification framework, grounded in PBL theory, is a reverse engineering project conducted at the freshman level of an undergraduate engineering program. More specifically, this project involves reverse engineering a hand-held mixer. A PBL classification model was used to classify the various aspects of the reverse engineering project according to indicators of structuredness, complexity, project duration, level of instruction, and level of teamwork. Given the multifaceted nature of PBL activities, we decomposed the PBL activity into multiple objectives and tasks, each of which were classified based on the PBL classification framework. This is unlike previous studies that focused on classifying the overall problems. For us, it was critical to decompose the problem in a series of objectives and tasks in order to truly characterize and classify each component of the problem. This is because each task of the project represented an aspect of the problem space. The classification framework we provide allows for any program to identify how the modification of tasks can affect the learning objectives associated with any PBL project. 
Application of this classification framework to the PBL experiences (such as the reverse engineering project herein) demonstrates (1) the dynamic nature of designing PBL experiences that incorporate varying levels of these indicators and (2) a structure for engineering programs that allows for better assessment of student learning outcomes related to PBL projects. Such a curriculum-wide model, grounded on strong assessment, has the potential for replication and generalizability across STEM programs nationwide.

The purpose of this paper is to provide structure for the classification of PBL projects conducted in an undergraduate engineering program. We also wish to demonstrate how such a classification framework could be used to enhance the educational experiences of students within those programs. Each of these goals is met by illustrating the implementation and the assessment of a sample PBL experience, a reverse engineering project, in an undergraduate course.

\section{Development of a PBL Classification Framework}

Although PBL is known to be an innovative pedagogy, both practitioners and researchers have not addressed the fact that PBL activities are not all created equal. In fact, as the nature of the problem changes, so do the inherent learning outcomes. We believe that by understanding the nature of the problem (i.e. PBL experience), we can better understand the learning process and how the specific features of the problem influence learning. Although there is limited information on this topic, the work of Jonassen and Hung ${ }^{8}$ was found to be most relevant. Their recent paper, titled "All Problems Are Not Created Equal: Implications for PBL," provided a framework for understanding and characterizing problems. They identified two "external factors" that contribute to problem difficulty: structuredness and complexity ${ }^{8}$. They reasoned that the less structured and the more complex the problem, the more difficult the problem would be for the student. This is not to say that well-structured problems are easy. Even wellstructured problems may encompass varying levels of complexity through the integration of multiple areas of domain knowledge. In Jonassen's and Hung's paper, structuredness and complexity have a set of interrelated indicators to determine the problem difficulty. Structuredness is determined by the problem's vagueness, the number of interpretations of the problem space, number of disciplines involved, the number of solution paths, and the emergence of variables in the problem space. Complexity is determined by the amount of knowledge the student has about the problem, the level of attainment of that knowledge, the length of the solution path, and the cognitive load required by the problem.

In the effort herein, we operationalized structuredness and complexity indicators based on Jonassen's and Hung's work in order to help us develop a framework for classifying the specific project tasks of a PBL activity. It is important to note that Jonassen's and Hung's framework is grounded on characterizing the overall problem. In our study and effort, we operationalized Jonassen's and Hung's framework to help us classify the multiple facets of the PBL experience, which we articulated as project objectives and tasks. In addition to operationalizing some of the indicators of complexity and structuredness, we also added other indicators to the classification framework.

In the PBL classification framework we derived from the work of Jonassen and $\mathrm{Hung}^{8}$, we made several modifications and additions. First, we wanted to increase the ease by which faculty with 
limited background in PBL theory could use the classification framework. Reducing the number of indicators allowed for the consensus among the rating of project tasks to occur more quickly. Second, for purposes of implementation, we wanted to remove PBL jargon that would make it difficult for practitioners to use. Allowing the faculty to determine the best ways to define and utilize the classification indicators was integral in the process of operationalizing Jonassen's and Hung's framework. Third, we wanted to align our classification framework with the program's philosophy on PBL. Not only did we want to classify the projects using theoretically based indicators of structuredness and complexity, we also wanted to classify them according to other indicators that are important to the program.

Table 1 illustrates the PBL classification indicators that we utilized during this effort. As stated above, the framework of Jonassen and $\mathrm{Hung}^{8}$ provided some fundamental inspiration during this process and aided us in operationalizing indicators to meet the needs and context of our effort. Their categorization is shown in the first column. Our modifications are shown in the second and third columns.

Table 1. Project Classification Indicators

\begin{tabular}{|c|c|c|}
\hline \multirow{2}{*}{$\begin{array}{l}\text { Classification } \\
\text { Indicators } \\
\text { (Jonassen and } \\
\left.\text { Hung }^{8}\right)\end{array}$} & \multicolumn{2}{|c|}{ Operationalizing Jonassen's and Hung's Classification Indicators } \\
\hline & $\begin{array}{l}\text { Modified } \\
\text { Classification } \\
\text { Indicators }\end{array}$ & $\begin{array}{l}\text { Description of Modified Classification Indicators } \\
\text { Operationalized for our Framework }\end{array}$ \\
\hline $\begin{array}{l}\text { Breadth of } \\
\text { Knowledge }\end{array}$ & $\begin{array}{l}\text { Domain } \\
\text { Knowledge }\end{array}$ & $\begin{array}{l}\text { What domain knowledge was needed to work and complete the } \\
\text { specific project task? }\end{array}$ \\
\hline Interdisciplinarity & $\begin{array}{l}\text { Domain } \\
\text { Knowledge } \\
\text { Disciplinarity }\end{array}$ & Does the project task involve knowledge from other disciplines? \\
\hline $\begin{array}{l}\text { Intricacy of } \\
\text { Procedures }\end{array}$ & \multirow{2}{*}{$\begin{array}{l}\text { Domain } \\
\text { Knowledge } \\
\text { Difficulty }\end{array}$} & \multirow{2}{*}{$\begin{array}{l}\text { How difficult is the domain knowledge required to complete the } \\
\text { project task? Were there knowledge, concepts, etc. that needed } \\
\text { to be simultaneously considered to work on the project task? }\end{array}$} \\
\hline Attainment Level & & \\
\hline $\begin{array}{l}\text { Heterogeneity of } \\
\text { Interpretations }\end{array}$ & \multirow{3}{*}{$\begin{array}{l}\text { Solution Path } \\
\text { Complexity }\end{array}$} & \multirow{3}{*}{$\begin{array}{l}\text { How complex was the solution path in order to complete the } \\
\text { project task? Were there aspects of the tasks that were unknown } \\
\text { or that would require the student to guess or make assumption in } \\
\text { order to complete the project task? Could the solution path or } \\
\text { execution of the project task be interpreted in multiple ways? } \\
\text { Did the execution of the project task lead to multiple solutions? }\end{array}$} \\
\hline $\begin{array}{l}\text { Competing } \\
\text { Alternatives }\end{array}$ & & \\
\hline Dynamicity & & \\
\hline \multirow{2}{*}{ Intransparency } & Structuredness & How would you rate the structuredness of the project task? \\
\hline & $\begin{array}{l}\text { Level of } \\
\text { Instruction } \\
\end{array}$ & $\begin{array}{l}\text { How would you rate the level of instruction that was provided in } \\
\text { regards to the specific project task? }\end{array}$ \\
\hline \multirow[t]{2}{*}{$\mathrm{N} / \mathrm{A}$} & $\begin{array}{l}\text { Team Size and } \\
\text { Makeup }\end{array}$ & Describe the team size and makeup. \\
\hline & $\begin{array}{l}\text { Duration of } \\
\text { Project Task }\end{array}$ & What was the duration of the project task? \\
\hline
\end{tabular}


As can be seen in Table 1, the operationalization of breadth of knowledge and the interdisciplinary indicators remain unchanged from the Jonassen and Hung ${ }^{8}$ framework. In the modified classification framework the two indicators continue to represent the depth and the types of knowledge required to solve the problem presented by the project. Intricacy of problemsolution procedures was combined with the attainment level of knowledge required to complete the tasks and renamed domain knowledge difficulty. Intransparency was renamed structuredness and level of instruction was added to its operationalization. This addition allowed us to account for the ways in which instruction methods provided by the professor may influence task structure or complexity. The heterogeneity of interpretations, legitimacy of competing alternatives, and dynamicity were enveloped by solution path complexity. Level of teamwork was also included to allow us to account for the fact that some tasks/problems will be solved individually and others in a team setting.

Unlike Jonassen and $\mathrm{Hung}^{8}$ who developed the framework to provide an overall classification of a problem, we decomposed the PBL activity into a set of project objectives and tasks, each of which were characterized. We took this approach because we acknowledge that most problems, particularly PBL-based ones, are multi-faceted with each facet having unique characteristics that lead to unique learning outcomes. This made for a more complex classification framework.

\section{Application of the PBL Classification Framework}

The classification framework was applied to a reverse engineering project in which students were placed in teams of three or four to "systematically" disassemble a hand-held mixer and perform a series of tasks to better understand the reverse engineering process. The project involved about 5 hours of classroom time to disassemble the device and inventory the parts and functions, as well as about 5 to 10 hours of out of class time for completion of the project report. Table 2 shows the objectives of the project as well as the corresponding tasks that students were expected to complete.

Table 2: Project objectives and project tasks for the reverse engineering PBL activity.

\begin{tabular}{|c|c|}
\hline $\begin{array}{c}\text { Project Objective: } \\
\text { Students will be able to... }\end{array}$ & $\begin{array}{l}\text { Project Task Where } \\
\text { Objective is Addressed }\end{array}$ \\
\hline \multirow{2}{*}{$\begin{array}{l}\text { 1. Name the steps in the reverse } \\
\text { engineering process and identify the } \\
\text { purpose of each. }\end{array}$} & A.Name the steps in the reverse engineering process. \\
\hline & $\begin{array}{l}\text { B. Describe the purpose of each step in the reverse } \\
\text { engineering process. }\end{array}$ \\
\hline $\begin{array}{l}\text { 2. Disassemble an electromechanical } \\
\text { device in a systematic manner using } \\
\text { video instructions. }\end{array}$ & $\begin{array}{l}\text { C. Using an instructional video and instructor assistance, } \\
\text { disassemble an electromechanical device in a } \\
\text { systematic manner. }\end{array}$ \\
\hline \multirow{3}{*}{$\begin{array}{l}\text { 3. Organize information about a product } \\
\text { in a way that describes a product's } \\
\text { make-up and functionality. }\end{array}$} & D.Prepare materials and parts $\mathrm{i}$ \\
\hline & E. Draw a concept map of how product parts interact. \\
\hline & $\begin{array}{l}\text { F. Draw a functional relation diagram describing how a } \\
\text { product functions. }\end{array}$ \\
\hline $\begin{array}{l}\text { 4. Propose a plausible improvement to } \\
\text { the product. }\end{array}$ & $\begin{array}{l}\text { G.Propose a design modification to improve the } \\
\text { functioning of the product. }\end{array}$ \\
\hline
\end{tabular}


The faculty and assessment specialists reviewed the mapping and alignment of each task to student learning objectives. Table 2 illustrates how each of the tasks were mapped to the objectives or learning outcomes for the project. Mapping these tasks back to the objectives helped to determine how well the objectives of the project were aligned with the specific tasks students were expected to complete. It also helped to determine at which point during the project the students met the overall project objectives.

Each of the seven project tasks (column two of Table 2) were classified according to indicators described in Table 1 (columns two and three). Although the classification of all seven tasks is not shown herein, Table 3 does show what a typical project task classification involved. A description of the domain knowledge and disciplinarity are given. Difficulty, level of instruction, structuredness, and solution path complexity are rated according to their respective scales. A brief rationale is also given for each of these ratings. Team size and makeup information is also provided. In this project, team size and makeup were the same across all tasks.

Table 3: Classification of Tasks

\begin{tabular}{|c|c|c|c|c|c|c|c|}
\hline & $\begin{array}{c}\text { Domain } \\
\text { Knowledge }\end{array}$ & $\begin{array}{c}\text { Domain } \\
\text { Knowledge } \\
\text { Disciplinarity } \\
\end{array}$ & $\begin{array}{c}\text { Domain } \\
\text { Knowledge } \\
\text { Difficulty } \\
\end{array}$ & $\begin{array}{c}\text { Level of } \\
\text { Instruction }\end{array}$ & Structuredness & $\begin{array}{l}\text { Complexity of } \\
\text { Solution Path }\end{array}$ & $\begin{array}{l}\text { Team Size and } \\
\text { Makeup }\end{array}$ \\
\hline Project Task & $\begin{array}{c}\text { List the } \\
\text { domain } \\
\text { knowledge } \\
\text { needed to } \\
\text { work and } \\
\text { complete this } \\
\text { task }\end{array}$ & $\begin{array}{l}\text { What are the } \\
\text { disciplinary } \\
\text { underpinnings } \\
\text { of this domain } \\
\text { knowledge? }\end{array}$ & $\begin{array}{l}\text { Please rate from } \\
1 \text { (Very Easy) to } \\
5 \text { (Very Difficult) } \\
\text { and describe in } \\
\text { your own words }\end{array}$ & $\begin{array}{c}\text { Please rate } \\
\text { from } 1 \text { (A lot }) \text { to } \\
5 \text { (Not at all) } \\
\begin{array}{c}\text { and describe in } \\
\text { your own } \\
\text { words. }\end{array}\end{array}$ & $\begin{array}{l}\text { Pleas rate from } \\
1 \text { (Very Well- } \\
\text { defined) to } 5 \\
\text { (Undefined) and } \\
\text { describe in your } \\
\text { own words. }\end{array}$ & $\begin{array}{l}\text { Please rate from } 1 \\
\text { (Not Complex) to } \\
5 \text { (Very Complex) } \\
\text { and describe in } \\
\text { your own words }\end{array}$ & $\begin{array}{c}\text { What was the } \\
\text { team size? List } \\
\text { the number and } \\
\text { describe the team } \\
\text { (disciplinarity, } \\
\text { academic level, } \\
\text { etc.) }\end{array}$ \\
\hline \multirow{2}{*}{$\begin{array}{l}\text { Task A: Name } \\
\text { the steps in the } \\
\text { reverse } \\
\text { engineering } \\
\text { process. }\end{array}$} & \multirow{2}{*}{$\begin{array}{l}\text { Lecture } \\
\text { material on } \\
\text { the reverse } \\
\text { engineering } \\
\text { process }\end{array}$} & \multirow{2}{*}{$\begin{array}{l}\text { General } \\
\text { engineering and } \\
\text { design }\end{array}$} & \multirow{2}{*}{\begin{tabular}{|l|}
1 \\
Listed directly from \\
lecture materials.
\end{tabular}} & 1 & \multirow{2}{*}{\begin{tabular}{|l|}
1 \\
Straight from \\
lecture materials.
\end{tabular}} & \multirow{2}{*}{\begin{tabular}{|l|}
1 \\
Straight-forward \\
and very linear
\end{tabular}} & $2-3$ \\
\hline & & & & $\begin{array}{l}\text { Required } \\
\text { classroom } \\
\text { content } \\
\text { lectures. }\end{array}$ & & & $\begin{array}{l}\text { Each team was } \\
\text { comprised of } \\
\text { freshmen } \\
\text { engineering } \\
\text { students }\end{array}$ \\
\hline \multirow[b]{2}{*}{$\begin{array}{l}\text { Task G: } \\
\text { Propose a } \\
\text { design } \\
\text { modification } \\
\text { to improve } \\
\text { functioning of } \\
\text { the product }\end{array}$} & \multirow{2}{*}{$\begin{array}{l}\text { Creativity } \\
\text { and basic } \\
\text { design skills }\end{array}$} & \multirow{2}{*}{$\begin{array}{l}\text { General } \\
\text { engineering and } \\
\text { design }\end{array}$} & \begin{tabular}{|l|l}
2 \\
\end{tabular} & 3 & \begin{tabular}{|l|}
4 \\
\end{tabular} & 3 & \begin{tabular}{||l|l|}
$2-3$ \\
\end{tabular} \\
\hline & & & $\begin{array}{l}\text { Spending sufficient } \\
\text { time to develop a } \\
\text { truly creative idea } \\
\text { was a challenge for } \\
\text { the students. }\end{array}$ & $\begin{array}{l}\text { Lots of out-of- } \\
\text { class questions } \\
\text { due to a lack of } \\
\text { confidence in } \\
\text { creative design } \\
\text { skills. }\end{array}$ & $\begin{array}{l}\text { Open ended with } \\
\text { no correct } \\
\text { answer, but a } \\
\text { fixed design goal }\end{array}$ & $\begin{array}{l}\text { Open ended with } \\
\text { multiple solutions }\end{array}$ & $\begin{array}{l}\text { Each team was } \\
\text { comprised of } \\
\text { freshmen } \\
\text { engineering } \\
\text { students }\end{array}$ \\
\hline
\end{tabular}

Based on the ratings of each project task, we came up with overall simplified characterizations as illustrated in Table 4. This overall characterization was assessed not only by the engineering instructor who designed and implemented the PBL activity, but also by the team of assessment specialists. More specifically, the second and third columns of Table 4 illustrate an overall project task classification (with the exception of level of teamwork, which was expected to be constant across all tasks given the team nature of this experience). While there were some differences in ratings between the assessment specialists and the faculty, the majority of the ratings were similar. This indicated agreement on how the tasks should be classified, which 
provides a framework for understanding the types of tasks that could be used to assist students in achieving the corresponding outcomes.

Table 4. Mapping of Project Objectives to Project Tasks and Classification by Assessment Specialists and Engineering Faculty Instructor.

\begin{tabular}{|c|c|c|}
\hline \multirow{2}{*}{$\begin{array}{c}\text { Project Task Where } \\
\text { Objective is Addressed }\end{array}$} & \multicolumn{2}{|c|}{ Project Task Classification } \\
\hline & By assessment specialist & $\begin{array}{l}\text { By engineering } \\
\text { faculty/instructor }\end{array}$ \\
\hline $\begin{array}{l}\text { A. Name the steps in the reverse } \\
\text { engineering process. }\end{array}$ & $\begin{array}{l}\text { Highly Structured } \\
\text { Not Complex } \\
\text { High Level of Instruction } \\
\end{array}$ & $\begin{array}{l}\text { Highly Structured } \\
\text { Not Complex } \\
\text { Slightly High Level of Instruction }\end{array}$ \\
\hline $\begin{array}{l}\text { B. Describe the purpose of each step } \\
\text { in the reverse engineering } \\
\text { process. }\end{array}$ & $\begin{array}{l}\text { Highly Structured } \\
\text { Not Complex } \\
\text { High Level of Instruction } \\
\end{array}$ & $\begin{array}{l}\text { Highly Structured } \\
\text { Not Complex } \\
\text { Slightly High Level of Instruction }\end{array}$ \\
\hline $\begin{array}{l}\text { C. Using an instructional video and } \\
\text { instructor assistance, disassemble } \\
\text { an electromechanical device in a } \\
\text { systematic manner. }\end{array}$ & $\begin{array}{l}\text { Highly Structured } \\
\text { Not Complex } \\
\text { High Level of Instruction }\end{array}$ & $\begin{array}{l}\text { Highly Structured } \\
\text { Not Complex } \\
\text { High Level of Instruction }\end{array}$ \\
\hline $\begin{array}{l}\text { D.Prepare materials and parts } \\
\text { inventories. }\end{array}$ & \begin{tabular}{|l|} 
Structured \\
Not Complex \\
Moderate Level of Instruction
\end{tabular} & $\begin{array}{l}\text { Highly Structured } \\
\text { Not Complex } \\
\text { High Level of Instruction }\end{array}$ \\
\hline $\begin{array}{l}\text { E. Draw a concept map of how } \\
\text { product parts interact. }\end{array}$ & \begin{tabular}{|l|} 
Structured \\
Not Complex \\
Moderate Level of Instruction \\
\end{tabular} & $\begin{array}{l}\text { Structured } \\
\text { Slightly Complex } \\
\text { High Level of Instruction }\end{array}$ \\
\hline $\begin{array}{l}\text { F. Draw a functional relation } \\
\text { diagram describing how a } \\
\text { product functions. }\end{array}$ & \begin{tabular}{|l|} 
Structured \\
Not Complex \\
Moderate Level of Instruction \\
\end{tabular} & $\begin{array}{l}\text { Structured } \\
\text { Slightly Complex } \\
\text { Moderate Level of Instruction }\end{array}$ \\
\hline $\begin{array}{l}\text { G.Propose a design modification to } \\
\text { improve the functioning of the } \\
\text { product. }\end{array}$ & $\begin{array}{l}\text { Unstructured } \\
\text { Moderately Complex } \\
\text { Low Level of Instruction } \\
\end{array}$ & $\begin{array}{l}\text { Slightly Unstructured } \\
\text { Moderately Complex } \\
\text { Moderate Level of Instruction }\end{array}$ \\
\hline
\end{tabular}

*All tasks were completed by students in teams of 3 or 4.

The implementation of this classification framework enabled faculty to consider each project task within the terms of the indicators of structure and complexity, as well as the other indicators important to the program. This allowed for the faculty to highlight the intricate parts of the problem space within the project, and identify how each of those parts or tasks related to the learning outcomes that are expected to be achieved.

By decomposing the project into classified tasks the faculty can conceptualize different learning experiences to achieve different outcomes. In this reverse engineering example, the learning outcomes of each task could be modified by adjusting the indicators that led to their current classification. For example, decreasing the level of instruction, increasing the complexity, and decreasing the structure of each task would make for a substantially different learning experience for the students. We could also change the device that needed to be reverse engineered. This would change the scale and scope of the project requiring a different set of skills and domain 
knowledge. Overall, this framework provided a useful tool for classifying the facets of the reverse engineering project, and appears to be feasible for use with other projects.

\section{Assessing the PBL Project}

Several data collection methods were used to gather information and guide the development of the classification framework. These methods included a review of the project description and materials, classroom observations of students, a review of students' finished products, focus groups, course evaluations and faculty interviews. The classification of each task in Table 4 was conducted with the assistance of educational assessment specialists.

Using the project documentation, the assessment specialists reviewed the learning outcomes of the project to verify that the objectives were student centered, clear, and measureable. These objectives were the starting point for identifying the essential tasks that constituted the project. This required any ambiguous or vague outcomes to be reworded or removed. The result of this process was the mapping of project tasks to the objectives. With the objectives and the tasks clearly aligned, the process of classifying those tasks could begin.

The classroom observations were conducted during two different sections when students were disassembling the hand-held mixers. During these observations, the assessment specialists identified themes related to the complexity or structure of tasks, the amount of instruction provided, and the amount of teamwork used. Observation notes indicated how the level of instruction affected the structure and complexity of the tasks. According to those notes, level of instruction seemed to have a mediatory effect on the complexity and structure of the tasks being completed. The assessment specialists also observed in some cases that students overestimated their ability to follow the solution path they were provided with and had to rely on trial and error to complete the tasks. These observations allowed the assessment specialists to make judgments on the levels of complexity, structure, instruction, and teamwork that occurred in the classroom.

To demonstrate completion of this reverse engineering project, students displayed their disassembly efforts. These were assessed by the course professor. Students also turned in a report that demonstrated the completion of all other tasks. These were assessed by both the professor and the assessment specialists. These reports demonstrated how well the students completed each task, the level of attainment of each learning outcome, and also provided further resources on which to base our classification of the tasks. Project tasks which were wellstructured and not complex were expected to be easy for the students to complete. This level of ease was reflected in grades for these tasks. For example, the procedure for creating the parts inventory was well-defined and lacked complexity. The grades for this portion of the project were high for all students.

The students were also given an opportunity to participate in focus groups to discuss their experiences participating in PBL projects throughout the semester. The focus groups were conducted at the end of the semester with the purpose of eliciting student experiences during all PBL projects implemented in the freshman engineering course, inclusive of the reverse engineering project. A total of 37 students participated. Students were asked about their level of satisfaction with the projects, their level of achievement of student learning outcomes associated 
with the projects, and their concerns about the implementation of the projects within the course. Common themes from the focus groups that specifically addressed the reverse engineering project were recorded. Student report data indicated:

a) students felt they had a lack of experience using some of the tools required to disassemble the mixer.

b) students desired more time to reflect on various aspects of the project before moving on to other project tasks.

c) students also preferred the group aspect of the project over working alone.

Student concerns about prior tool experience were not initially considered in the rating of complexity for this task. This suggests that the complexity level of the disassembly task may be higher than initially expected by the faculty and assessment specialists. This led faculty to reconsider the preparation time allotted for practice with tools before beginning the disassembly task of the project. Student concerns about reflection time were unanticipated. Students were given an opportunity to reflect when writing final reports on the project. However, their expectations of reflection may differ from the faculty members' expectations. Student appraisal of the teamwork aspect of the project was expected as classroom observations had provided some evidence of the quality of teamwork exhibited by the students.

In the end-of-semester survey, students noted a lack of difficulty during the disassembly process of the reverse engineering project. These sentiments were expected given that a video recording of the disassembly was provided to students. This video was expected to provide a high level of guidance for students and decrease the difficulty of the disassembly task. This decreased difficulty was expected as demonstrated by the ratings of the task by the faculty member and the assessment specialists. Therefore, our expectation of student experiences in the disassembly process was verified by student opinions of the process.

Further, students were asked to give their overall opinion of the reverse engineering project in their course evaluations. When asked about how strongly they agree with the statement "The reverse engineering project was a valuable learning experience," 97\% of the 77 students either "agreed" or "strongly agreed" with the statement. This level of satisfaction was corroborated in the project evaluation survey and the focus groups.

Taken together, each of these data collection methods provided insight into the classification of each task. This is where the fidelity of each project was observed. In practice, the classification of the tasks should be conducted prior to the project implementation. Then observations should serve as a check to ensure that the level of indicator used to classify each project task is demonstrated through the student experiences. They should also provide further evidence for the rationale of selecting each level of indicator for each task. If student experiences reflect the prescribed indicators of task complexity and structure, then modification of those tasks and the indicators associated with them should have an effect on the student learning outcomes expected. In this study the classification of the project tasks occurred simultaneously with the project, the observations, and the focus groups. The ratings for each indicator were modified again once all information was gathered and discussed among the faculty and the assessment specialists. 


\section{Summary}

The implementation of PBL projects within an undergraduate engineering program should be well thought out and driven by the goals and student learning outcomes for the course and the program. When implemented this way, PBL provides the added benefit of assisting programs in identifying how knowledge, skills, and abilities develop in undergraduate engineering students. However, this dynamic use of PBL in undergraduate engineering requires that users (i.e. faculty practitioners) develop a framework for understanding how the PBL project contributes to student learning and impacts the learning outcomes.

This study provided a framework that can be used for the classification PBL projects, which are not all created equal. As seen with the reverse engineering example, the implementation of PBL is very complex. It allows us to not only understand whether students are able to solve problems, but also understand the skills or abilities that are required to solve the specified problem. These skills and abilities are demonstrated through the completion of tasks associated with the problem. It is the classification of these tasks that allow for the understanding of the skills and abilities required to solve the problem. Therefore, the classification of projects is essential for programs and students to reap the full benefits of PBL, which include the understanding of skills undergraduate engineering students develop.

Identifying an appropriate way to use projects should be left to the discretion of the program. As previously mentioned, the implementation of PBL will differ among programs for many reasons. However, the classification of projects should be a constant procedure across programs. Without classification, the dynamic nature of PBL will not be realized by the program. The program may not obtain the full benefits of providing dynamic projects that allow for the assessment of multiple learning outcomes.

A major goal of this study was to demonstrate novel use of a classification framework for PBL projects. We wanted to demonstrate the importance of this classification framework, as well as its feasibility. We were able to determine that the implementation of a classification framework to classify a PBL project can provide meaningful feedback to the engineering program about the nature of the projects being conducted and the student learning outcomes being achieved. Here we have provided a framework for that process. The implementation of the classification framework requires programs to identify the major tasks associated with each PBL project. It also requires programs to identify the learning outcomes associated with each project. This helps to determine how well each project assists students in attainment of the desired student learning outcomes.

Although, herein, the example PBL activity that was presented pertained to a reverse engineering project, there were several other PBL activities that were also part of the freshman engineering course. Though some of the other projects provided differing levels of complexity and structure, we chose to illustrate the use of a PBL classification framework with the reverse engineering project because it embodied tasks that reflect the broad range of tasks required at this academic level. It was also chosen to demonstrate how the problem space can be decomposed into the variety of tasks. 
The scope of this paper was to demonstrate use of a classification system for PBL projects in a freshman engineering course. Our future work will illustrate the use of the PBL classification framework for other projects at the freshman level, as well as other academic levels. We will also continue to improve the development and implementation of the classification framework and demonstrate the benefits of its use in undergraduate engineering programs. Understanding how PBL projects could be classified will assist the undergraduate engineering community in identifying and developing the types of projects that provide students with the best opportunities to achieve their learning outcomes. Another long-term goal is to use such a PBL classification to characterize other highly promoted projects in engineering education such as capstone design projects which by nature are more complex and ill-structured.

\section{Limitations}

Future studies should also address the limitations within the current study. The indicators of complexity and structuredness were developed while the reverse engineering project was in progress. This did not allow us to develop a priori classification ratings for each of the indicators prior to students beginning their project. An a priori classification rating would allow us to confirm whether the structuredness and complexity conceptualized by the faculty held true. Therefore, our current ratings represent informed judgments based on observations, deliverables, and focus groups. The next iteration of this classification model will allow us to confirm our hypotheses about the ratings for this reverse engineering project.

\section{Acknowledgments}

The authors would like to acknowledge the support of the National Science Foundation Awards \#DUE-0837465 (NSF CCLI - "Design and Implementation of an Innovative Problem-based Learning Model and Assessment Tools in Undergraduate Engineering Education”) and \#EEC0846468 (NSF CAREER - "Characterizing, Understanding, and Integrating Complex Problem Solving in Engineering Education”). The views expressed in this paper are those of the authors and do not necessarily represent those of the National Science Foundation. We would also like to thank the students who participated in this study.

\section{Bibliography}

1. Barrows, H.S. (1985). How to design a problem-based curriculum for the preclinical years. New York Springer Publishing Co.

2. Hmelo-Silver, C. E. (2004). Problem-based learning: What and how do students learn? Educational Psychology Review, 16, 235-266.

3. Norman, G. R., \& Schmidt, H. G. (1992). The psychological basis of problem based learning: A review of the evidence. Academic Medicine, 67,557-565.

4. Dyer, S.A., \& Schmalzel, J.L. (1998). Macroelectronics: A gateway to electronics and instrumentation education," IEEE Trans. Instrum. Meas., 47 (6), 1507-1511.

5. Pierrakos O., R. Kander, E. Pappas, R. Prins, Nov. 2008, “An Innovative Engineering Curriculum at James Madison University: Transcending Disciplinary Boundaries Through Innovative Problem Based Learning Practices," ASME International Mechanical Engineering Congress \& Exposition, Boston, MA

6. Savin-Baden, M. \& Major, C.H. (2004) Foundations of Problem-based Learning. Buckingham: SRHE/Open University Press. 
7. Van Berkel, H. \& Schmidt, H.G. (2001). Motivation to commit oneself as a determinant of achievement in problem-based learning. Higher Education 40: 231-242.

8. Jonassen, D.H., \& Hung, W. (2008). All Problems are not equal: Implications for PBL. Interdisciplinary Journal of Problem-Based Learning, 2 (2), 6-28. 